\title{
In memoriam Francesco Le Moli (1943-2008)
}

\author{
A. Mori · D. A. Grasso
}

Published online: 2 April 2009

(c) Birkhäuser Verlag, Basel/Switzerland 2009

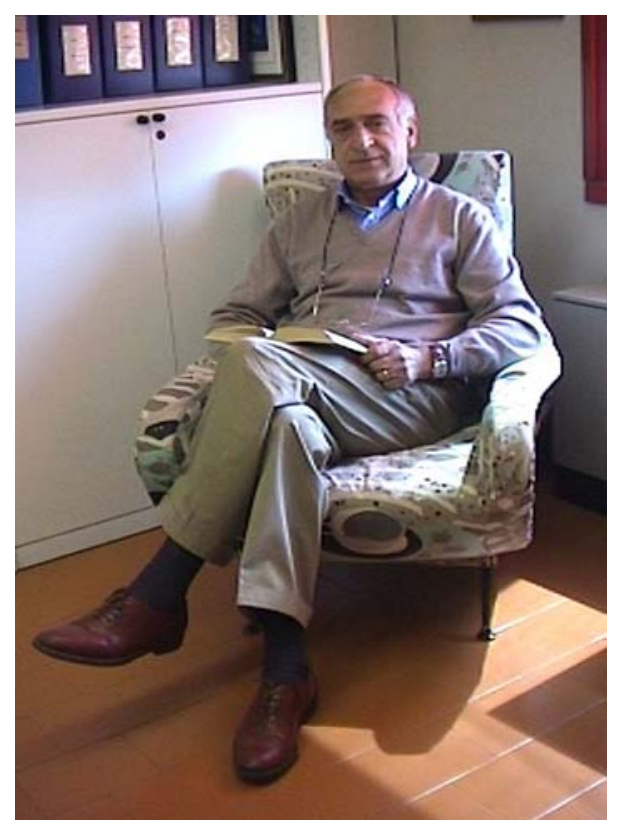

Last year, on 18 April, Francesco Le Moli passed away after a brief and acute disease, leaving an overwhelming gap in the Italian and international scientific community. He was born in Mosciano S. Angelo (Teramo, Italy) on 15 November 1943 but grew up in Parma where he completed his M.Sc. Degree in Natural Sciences under the supervision of Professor Danilo Mainardi in 1969. After graduation, he soon began his academic career as teacher of Zoology at the Faculty of Science.

\footnotetext{
A. Mori $(\bowtie) \cdot$ D. A. Grasso

Department of Evolutionary and Functional Biology, University of Parma, Via Usberti 11/A, 43100 Parma, Italy

e-mail: alessandra.mori@unipr.it

D. A. Grasso

e-mail: donato.grasso@unipr.it
}

His first researches were focused on the reproductive behaviour in Drosophila, the predatory behaviour of Scutigera coleoptrata and the distribution of different fish species in the Po river. His scientific fame, however, remains especially linked to his studies on the ethology of Formicidae. Firstly, in the 70s', he showed the role of early learning in the ontogeny of cocoon care behaviour and the development of interindividual relations in some species of the Formica rufa group. The results allowed him to suggest a hypothesis on the origin of slave species: in these ants the nestmate recognition is based more on living together than kinship. In fact, early learning phenomena explain the altruistic behaviour of slaves towards the slave-makers in the dulotic colonies. Afterwards, in the 80s', he analysed the intra- and interspecific aggressiveness in species of red wood-ants, describing for the first time the behavioural items characteristic of aggressive displays of these insects. Moreover, as a result of these studies, he supported the possibility to use the aggression test as a taxonomic tool in the Formica rufa group. The etho-ecology of the European Amazon ant Polyergus rufescens was the following target of his research during the 90s'. In particular he focused his attention on the reproductive strategies, colony foundation, raiding behaviour and orientation of this obligatory slavemaking ant. Most recent research fields were related to various aspects of communication, social parasitism, territoriality, and resource competition in the ant genera Formica, Polyergus and Messor.

Francesco Le Moli was author of more than 200 scientific papers in international journals and organiser of many scientific activities, but was also involved in popular science.

His scientific career was placed side by side by a not less bright career as university teacher. As full Professor of Zoology he spent a four years period in Perugia, but in 
1990 he came back to Parma where he spent the rest of his career in the Department of Evolutionary and Functional Biology.

In Parma, he was constantly involved in many activities in the Curriculum for the Degree in Natural Sciences and held highly responsible positions in the Rectorate. He was Coordinator of the Doctorate in "Ethology" (Universities of Firenze, Parma and Pisa) and in "Biology of Behaviour" (University of Parma). He was also founding member and President of the Italian Section of IUSSI (International
Union for the Study of Social Insects), President of the Italian Society for the Study of Animal Behaviour, and member of the Italian Union of Zoology.

Eminent scientist and backbone of the Laboratory of Myrmecology at the Department of Evolutionary and Functional Biology at the University of Parma, Francesco Le Moli continues to live not only in the results of his studies, but also in the hearth of all those people who like us shared many moments of everyday life with him and many years of enthusiastic work. 